\title{
A comparison of the techniques of direct pars interarticularis repairs for spondylolysis and low-grade spondylolisthesis: a meta-analysis
}

\author{
Nasser Mohammed, MD, MCh, Devi Prasad Patra, MD, MCh, Vinayak Narayan, MD, MCh, \\ Amey R. Savardekar, MCh, Rimal Hanif Dossani, MD, Papireddy Bollam, MD, MSChe, \\ Shyamal Bir, MD, PhD, and Anil Nanda, MD, MPH
}

Department of Neurosurgery, LSU-HSC, Shreveport, Louisiana

OBJECTIVE Spondylosis with or without spondylolisthesis that does not respond to conservative management has an excellent outcome with direct pars interarticularis repair. Direct repair preserves the segmental spinal motion. A number of operative techniques for direct repair are practiced; however, the procedure of choice is not clearly defined. The present study aims to clarify the advantages and disadvantages of the different operative techniques and their outcomes.

METHODS A meta-analysis was conducted in accordance with the PRISMA (Preferred Reporting Items for Systematic Reviews and Meta-Analyses) guidelines. The following databases were searched: PubMed, Cochrane Library, Web of Science, and CINAHL (Cumulative Index to Nursing and Allied Health Literature). Studies of patients with spondylolysis with or without low-grade spondylolisthesis who underwent direct repair were included. The patients were divided into 4 groups based on the operative technique used: the Buck repair group, Scott repair group, Morscher repair group, and pedicle screw-based repair group. The pooled data were analyzed using the DerSimonian and Laird random-effects model. Tests for bias and heterogeneity were performed. The $\mathrm{l}^{2}$ statistic was calculated, and the results were analyzed. Statistical analysis was performed using StatsDirect version 2.

RESULTS Forty-six studies consisting of 900 patients were included in the study. The majority of the patients were in their 2nd decade of life. The Buck group included 19 studies with 305 patients; the Scott group had 8 studies with 162 patients. The Morscher method included 5 studies with 193 patients, and the pedicle group included 14 studies with 240 patients. The overall pooled fusion, complication, and outcome rates were calculated. The pooled rates for fusion for the Buck, Scott, Morscher, and pedicle screw groups were $83.53 \%, 81.57 \%, 77.72 \%$, and $90.21 \%$, respectively. The pooled complication rates for the Buck, Scott, Morscher, and pedicle screw groups were 13.41\%, 22.35\%, 27.42\%, and 12.8\%, respectively, and the pooled positive outcome rates for the Buck, Scott, Morscher, and pedicle screw groups were $84.33 \%, 82.49 \%, 80.30 \%$, and $80.1 \%$, respectively. The pedicle group had the best fusion rate and lowest complication rate.

CONCLUSIONS The pedicle screw-based direct pars repair for spondylolysis and low-grade spondylolisthesis is the best choice of procedure, with the highest fusion and lowest complication rates, followed by the Buck repair. The Morscher and Scott repairs were associated with a high rate of complication and lower rates of fusion.

https://thejns.org/doi/abs/10.3171/2017.11.FOCUS17581

KEY WORDS direct repair; Buck repair; Scott repair; Morscher repair; spondylolysis; spondylolisthesis; pedicle screw-rod system; pedicle screw-hook system

$\mathrm{T}$ HE bipedal gait of Homo sapiens has an evolutionary advantage to our survival but has put a biomechanical disadvantage on the lumbar spine. Spondylolysis is defined as a defect of the pars interarticularis, either unilateral or bilateral; it is estimated to occur in
$3 \%-7 \%$ of the adult population. ${ }^{3}$ Sport activities carry a higher risk of spondylolysis with repetitive axial loading and hyperextension. The incidence of spondylolysis has been reported to be as high as 55\% in fast bowlers. ${ }^{14}$ The repeated stresses that fall on the pars in highly demanding

ABBREVIATIONS BMP = bone morphogenetic protein

SUBMITTED September 2, 2017. ACCEPTED November 1, 2017.

INCLUDE WHEN CITING DOI: 10.3171/2017.11.FOCUS17581. 
sports, such as weight lifting, cricket, soccer, and gymnastics, result in stress fractures. In most cases, spondylolysis and low-grade spondylolisthesis remain asymptomatic. ${ }^{3}$ However, in some cases, the pain can become disabling, prevent the patient from working, and progress to spondylolisthesis. Conservative management is the gold standard as the initial treatment of spondylolysis. Surgical treatment is advised in patients who have disabling symptoms despite conservative management or when there is a progression to spondylolisthesis. ${ }^{40}$ Intersegmental fusion would unnecessarily lead to stiffness of the spine and adjacent-segment disease and degeneration, especially in young patients. ${ }^{44}$ Therefore, there is much interest in direct repair of the pars interarticularis. Direct repair focuses on repair of the pars without causing motion restriction in the adjacent segments. The aim is to preserve spinal segmental motion and restore normal anatomy. There are many types of direct repair, with differing biomechanical properties. However, there is a lack of clarity regarding the surgical procedure of choice. The purpose of this study was to perform a systematic review and investigate differences in the fusion rate, complications, and outcomes between the following 4 types of direct pars repair: Buck repair, ${ }^{6}$ Scott repair, ${ }^{29}$ Morscher repair, ${ }^{28}$ and pedicle screw-based repair.

\section{Methods}

We performed a systematic review to identify the fusion rate, complication rate, and rate of positive outcome in the different techniques of direct pars interarticularis repair. A detailed protocol about the literature search, inclusion/exclusion criteria, selection of cases, and statistical methodology was developed. The PRISMA (Preferred Reporting Items for Systematic Reviews and Meta-Analyses) guidelines were followed (Fig. 1A). Two investigators (N.M. and V.N.) performed the literature search. To minimize selection bias, 2 reviewers (A.R.S. and D.P.P.) reviewed the articles independently. In case of doubt, a mutual consensus was reached after discussion.

\section{Literature Search Strategy}

A computerized Web search was performed of the titles and abstracts from January 1960 to June 2017 in the PubMed, Cochrane Library, Web of Science, and CINAHL (Cumulative Index to Nursing and Allied Health Literature) databases. A combination of key word searches were made to build a search strategy; non-English-language literature was also searched. Three non-English-language articles were reviewed after translation. An independent Web search was performed with the key words to include any unpublished literature. Key words that were used to build the search directory were "spondylolysis," "spondylolisthesis," "pars interarticularis," "direct repair," "Buck's fusion," "Scott's repair," and "Morscher's repair." Additional search terms used were "repair," "surgery," "fusion," and "complications."

\section{Bias Assessment}

Two investigators independently reviewed all articles to eliminate selection bias. A meta-analysis of proportions was performed. The present study includes only observational studies, and bias would be expected. All included studies were retrospective observational studies; no randomized controlled trials were found. For each subsection of the meta-analysis, bias indicator tests, specifically the Begg-Mazumdar and Egger tests, were performed. Funnel plots were created to check the heterogeneity of the studies (Fig. 1B). The Q statistic and $\mathrm{I}^{2}$ were calculated to assess heterogeneity. The $\mathrm{I}^{2}$ values in the Buck repair group and the pedicle repair group were low. The $\mathrm{I}^{2}$ values in the Scott repair group and Morscher repair group were high, suggesting increased heterogeneity. The Begg-Mazumdar test showed low power in the Scott repair group and Morscher repair group.

\section{Inclusion and Exclusion Criteria}

Studies of patients who had spondylosis with or without low-grade spondylolisthesis and who underwent surgery for direct pars interarticularis repair were selected from the literature and included in this meta-analysis. Age was not considered a criterion for inclusion in the study. Single case reports and small case series with fewer than 5 cases were excluded. Only direct repairs were selected. Patients who underwent fusion with adjacent segments or whose procedures involved facet joint fusion were excluded. Symptomatic spondylolysis not responding to conservative management and low-grade spondylolisthesis (Meyerding classification ${ }^{27}$ grades I and II) only were considered.

Patients with associated pathologies, such as spinal canal stenosis, disc degeneration, and radiculopathy, were excluded. Patients with both sporting and nonsporting backgrounds were included.

\section{Statistical Analysis}

Statistical analysis was done using StatsDirect statistical software (version 2.7.9, StatsDirect Ltd.). Due to the inherent heterogeneity of observational studies, the random-effects model was used for the meta-analysis. The meta-analysis of proportions was carried out, along with the test for heterogeneity, and the $\mathrm{I}^{2}$ value and Q statistic were evaluated. The DerSimonian and Laird model was used to calculate the pooled effect. Forest plots were charted for each group, analyzing the pooled fusion rate, complication rate, and outcome. For each subsection of the meta-analysis, bias assessment was done using the BeggMazumdar and Egger tests. Funnel plots were generated for each subset of the meta-analysis. The $\mathrm{I}^{2}$ value ranged from $0 \%$ to as high as $82 \%$ in the various groups of metaanalysis, suggesting a wide variation and heterogeneity across the included studies.

\section{Results}

Forty-six studies reporting on 900 patients who matched the inclusion criterion were selected for analysis (Table 1). The mean age ranged from 12 to 38 years. The average age was younger than 20 years in 25 studies. In only 4 studies was the average age older than 30 years; the majority of patients were in their 2 nd decade of life. The percentage of males was higher in the majority of the studies. Nine studies included patients exclusively from a 

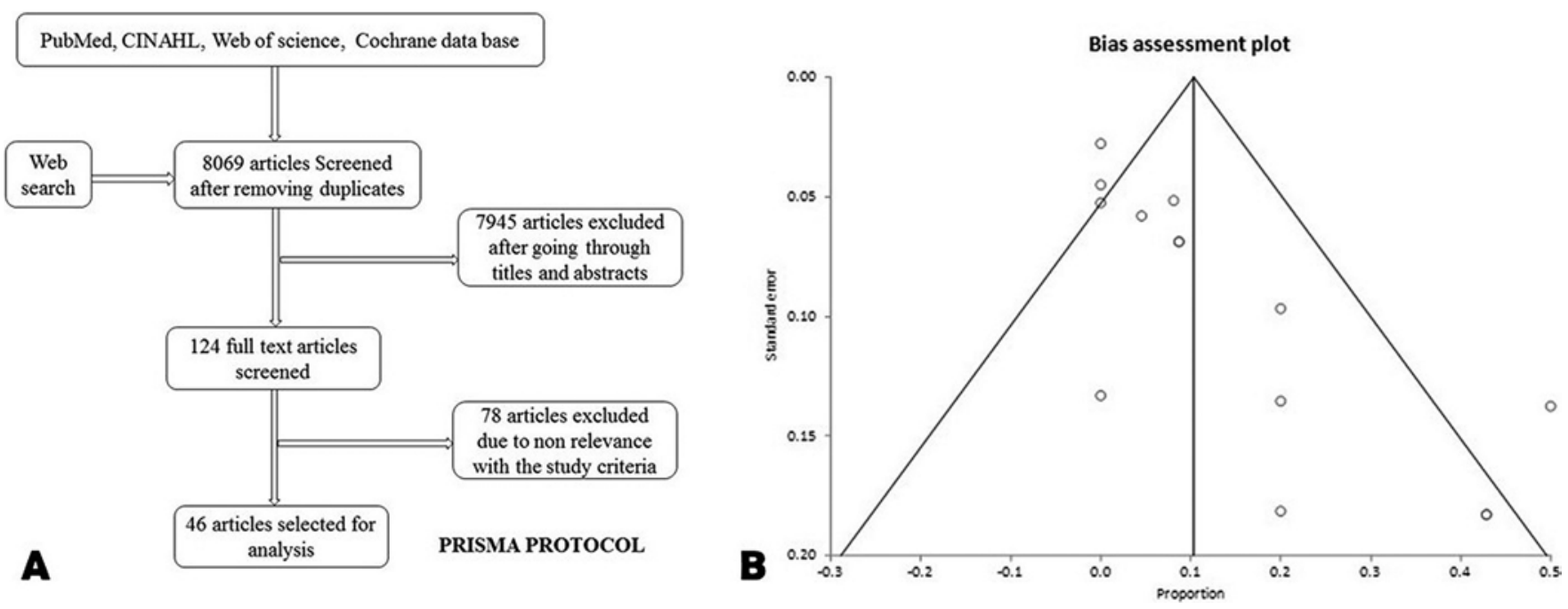

FIG. 1. A: PRISMA protocol showing the selection of cases. B: Funnel plot for the pedicle group showing asymmetrical distribution indicating presence of bias.

sporting background. Preoperative evaluation was done by examining flexion and extension radiographs, CT scans, MR images, and, in some studies, SPECT scans. Five studies included patients who were from sport and nonsport backgrounds. In 4 series, the authors used a minimally invasive approach for the Buck repair. ${ }^{10,12,21,51}$ Three studies used bone morphogenetic protein (BMP) to aid the fusion. Eight studies used pedicle screws with laminar hooks, and 4 studies used pedicle screws with a wiring technique. The proportion of patients with low-grade spondylolisthesis ranged from $5.26 \%{ }^{33}$ to $100 \%$ 7,30,47 in the included studies. While most studies included cases of low-grade spondylolisthesis, the exact proportion of cases was mentioned in only 16 studies.

Based on the surgical techniques used to repair the pars, the studies were grouped broadly into 4 categories. Buck's technique of repair was used in the first group. In this technique, a screw is passed across the pars defect. In this group, 19 studies with 305 patients were included. The Scott wiring technique was used in the second group. In this technique, a wire is wound around the transverse process and spinous process to stabilize the pars defect. Eight studies with 162 patients were included in this group. The Morscher method was used in 5 studies with 193 patients. The fourth group included 14 studies accounting for 240 patients who underwent pedicle screw-based repair. The purpose of this study was to investigate differences in the fusion rate, complications, and positive outcomes between the 4 broad categories of the pars repair. There were no prospective randomized studies addressing this issue. The fusion rate, complication rate, and positive outcome rate were compared between the groups (Table 2).

\section{Fusion Rate}

Fusion was assessed on radiographs in the majority of studies; CT scans were used in 9 studies. ${ }^{7,9,10,12,17,18,21,31,34}$ Ivanic et al..$^{18}$ evaluated CT scans only in cases of doubtful fusion. The remaining studies did not mention the method used for assessing fusion. The pooled rates for fusion for the Buck, Scott, Morscher, and pedicle screw groups were $83.53 \%, 81.57 \%, 77.72 \%$, and $90.21 \%$, respectively. The pooled fusion rates were highest for pedicle screwbased repairs and lowest for the Morscher method. The Buck method had the second highest fusion rate after the pedicle screw systems (Fig. 2).

\section{Complication Rate}

The complications of the different procedures were specified in most studies; 8 studies lacked specification. Both immediate and late complications were included in the analysis. The pooled complication rates for the Buck, Scott, Morscher, and pedicle screw groups were $13.41 \%$, $22.35 \%, 27.42 \%$, and $12.8 \%$, respectively. The complications were lowest for the pedicle screw-based repairs, followed by the Buck repair. The highest complication rates were observed in the Morscher method.

While some complications, such as superficial wound infections, were common to all 4 groups, some were specific to the type of repair used. Root irritation was more often observed in the Buck group, followed by the Morscher group, than in the other 2 groups. Wire breakage was the prominent complication for the Scott repair and resulted in nonunion. Transverse process fracture and wire protrusions were specific to the Scott group. The Morscher method was associated with a high incidence of nonunion and implant loosening. The pedicle screw-based group had the least incidence of superficial wound infection, nonunion, and implant loosening or pullout (Fig. 3).

\section{Outcome Analysis}

In most of the studies, the outcome was measured using nonstandardized scales, such as the Henderson criteria, Macnab criteria, modified Macnab criteria, and Odom criteria. Only 5 studies reported outcomes on standardized scales, such as the Oswestry Disability Index or the Japanese Orthopaedic Association scale. For analyzing the outcome measures in the present study, cases in which 


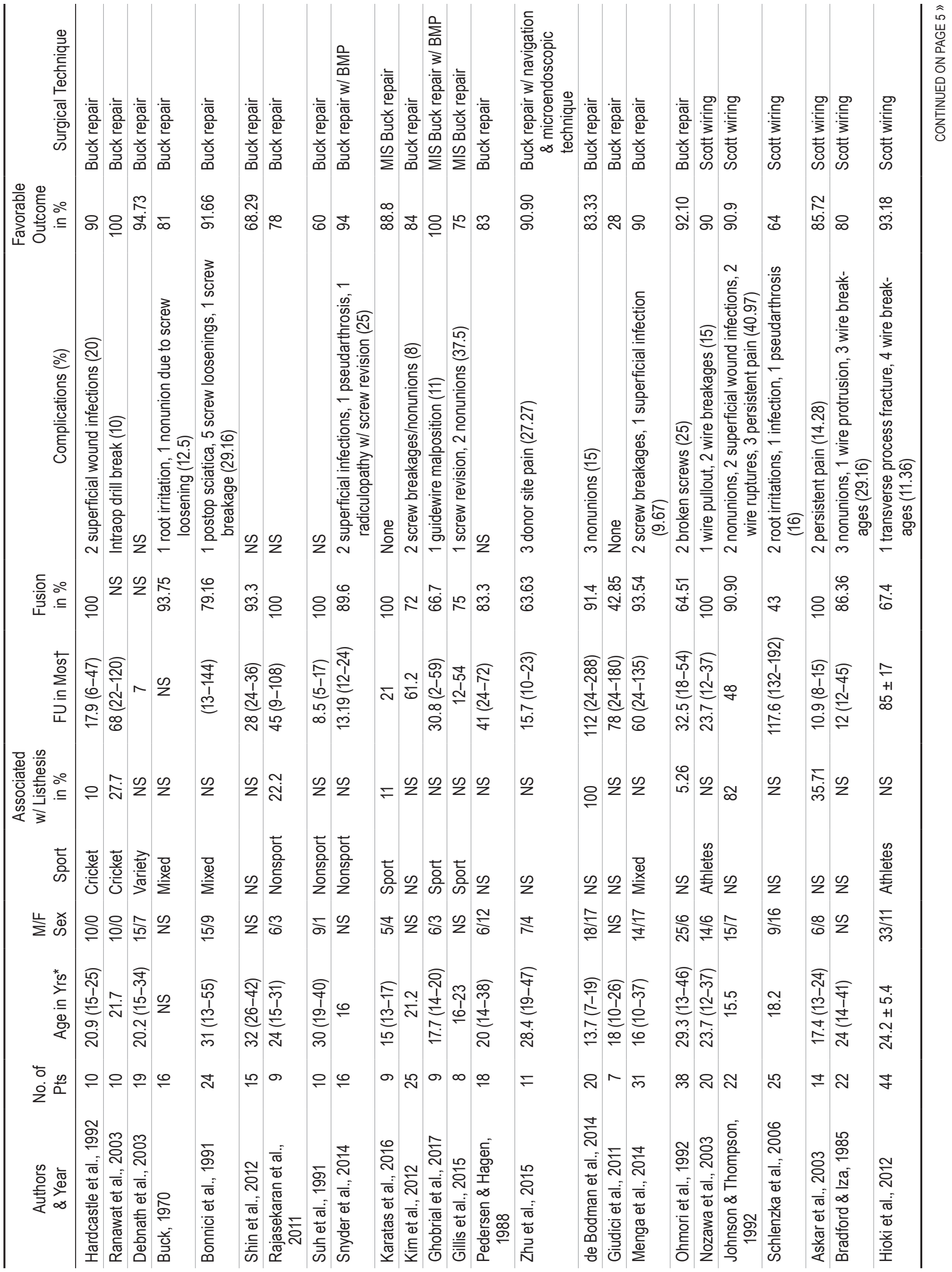




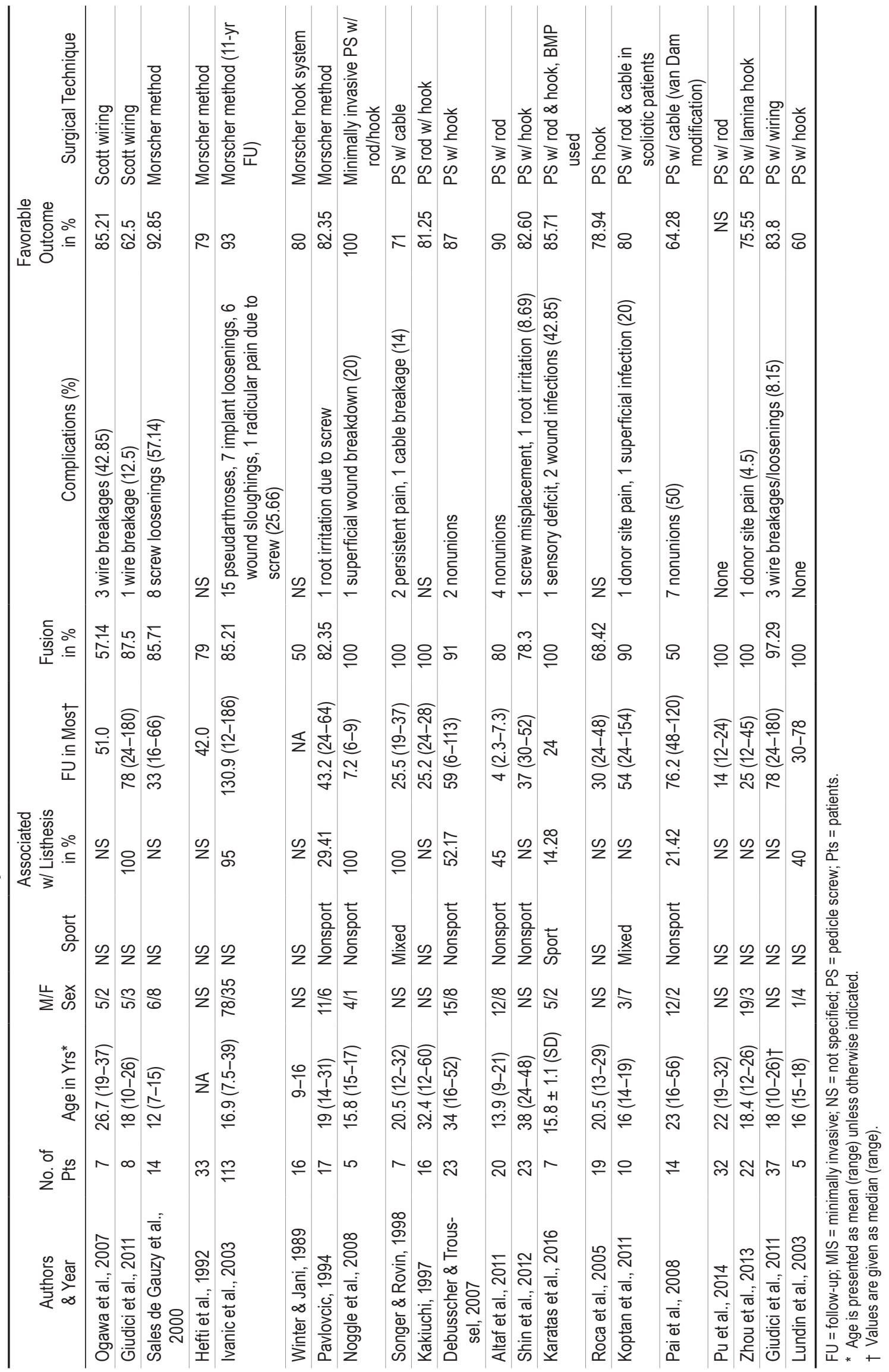


TABLE 2. Pooled fusion, complication, and favorable outcome rates in 4 groups of direct pars interarticularis repairs

\begin{tabular}{lccccc}
\hline \multicolumn{1}{c}{ Technique } & $\begin{array}{c}\text { No. of } \\
\text { Pts }\end{array}$ & $\begin{array}{c}\text { No. of } \\
\text { Studies }\end{array}$ & $\begin{array}{c}\text { Pooled Fusion Rate } \\
(95 \% \mathrm{Cl})\end{array}$ & $\begin{array}{c}\text { Pooled Complication Rate } \\
(95 \% \mathrm{Cl})\end{array}$ & $\begin{array}{c}\text { Pooled Positive Outcome Rate } \\
(95 \% \mathrm{Cl})\end{array}$ \\
\hline Buck repair & 305 & 19 & $83.53 \%(76-89 \%)$ & $13.41 \%(8-18 \%)$ & $84.33 \%(78-89 \%)$ \\
\hline Scott repair & 162 & 8 & $81.57 \%(65-93 \%)$ & $22.35 \%(14-31 \%)$ & $82.49 \%(73-89 \%)$ \\
\hline Morscher repair & 193 & 5 & $77.72 \%(66-86 \%)$ & $27.42 \%(8-51 \%)$ & $80.30 \%(80-88 \%)$ \\
\hline PS-based repair & 240 & 14 & $90.21 \%(82-96 \%)$ & $12.8 \%(6-21 \%)$ & $80.1 \%(74-85 \%)$ \\
\hline
\end{tabular}

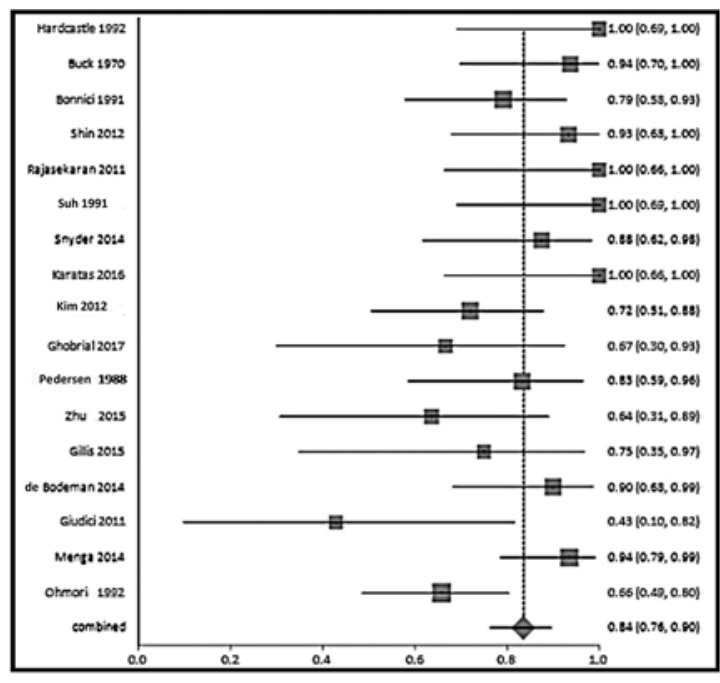

A. Buck's Repair: Pooled fusion rate $84 \%$

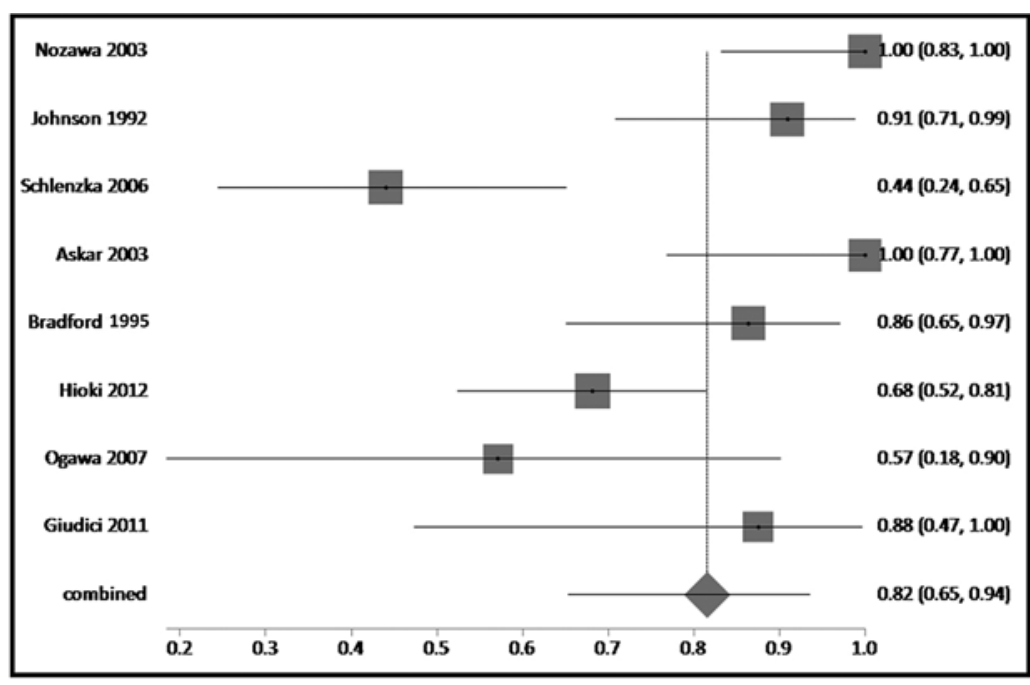

B. Scott's Repair: Pooled fusion rate $82 \%$

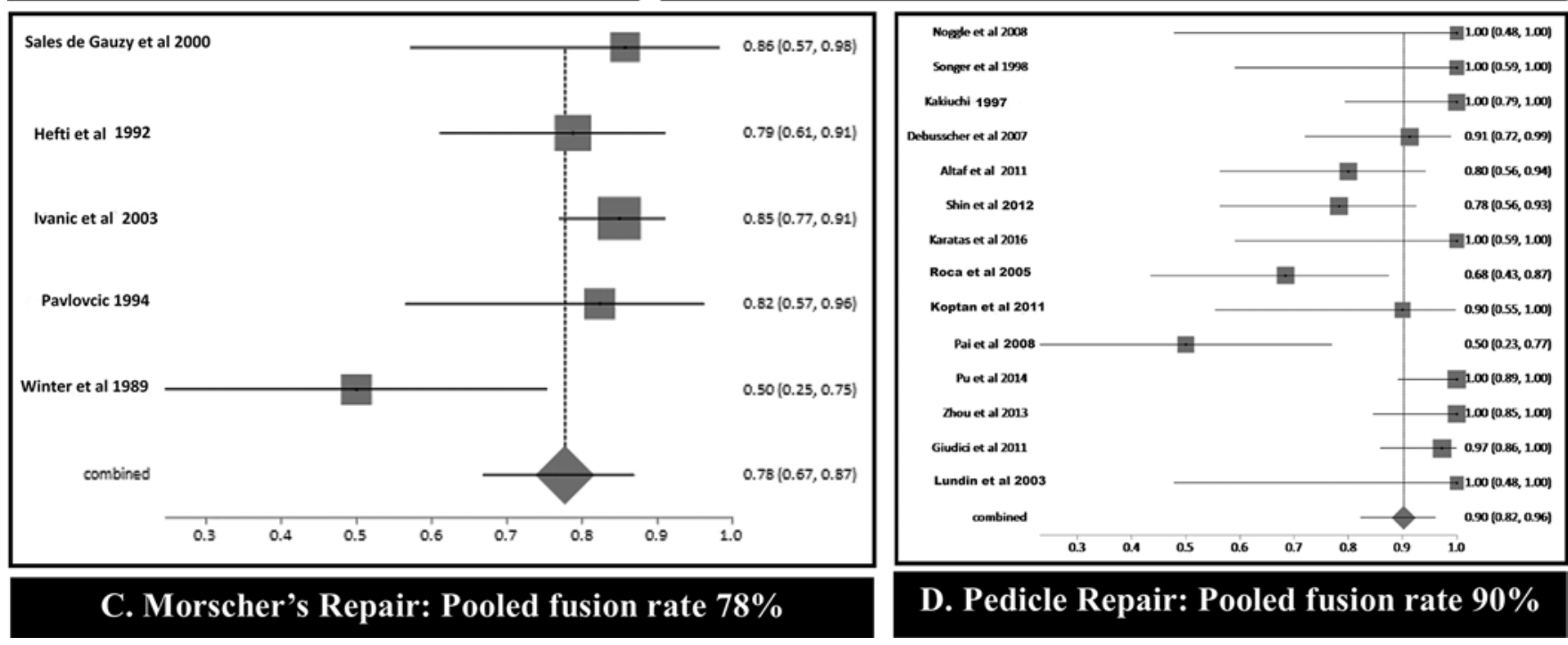

FIG. 2. Pooled proportional meta-analysis of the fusion rate. A: The Buck repair showed a pooled fusion rate of $84 \% .1^{2}=54.9 \%$. Random effects: pooled proportion $=0.835393(95 \%$ Cl 0.763996-0.896067). Begg-Mazumdar: Kendall's tau $=-0.477612, p=$ 0.0092. Egger: bias $=-3.086419(95 \% \mathrm{Cl}=-5.234691$ to -0.938148$), p=0.0079$. B: The Scott repair showed a pooled fusion rate of $82 \%$. $\left.\right|^{2}=82 \%$. Random effects: pooled proportion $=0.815706(95 \% \mathrm{Cl} 0.65304-0.935116)$. Begg-Mazumdar: Kendall's tau $=-0.571429, p=0.0312$ (low power). Egger: bias $=-4.067637(95 \% \mathrm{Cl}-8.329782$ to 0.194509$), p=0.0582$. C: The Morscher repair showed a pooled fusion rate of $78 \% .1^{2}=53.9 \%$. Random effects: pooled proportion $=0.777205(95 \% \mathrm{Cl}$ 0.668954-0.869173). Begg-Mazumdar: Kendall's tau $=-0.4, p=0.2333$ (low power). Egger: bias $=-1.596565(95 \% \mathrm{Cl}-5.142773$ to 1.949642$), p=0.2473$. D: The pedicle screw repair showed a pooled fusion rate of $90 \%$. $I^{2}=68.9 \%$. Random effects: pooled proportion $=0.902137(95 \% \mathrm{Cl} 0.822408-0.960009)$. Begg-Mazumdar: Kendall's tau $=-0.438202, p=0.0364$. Egger: bias $=$ $-1.719656(95 \% \mathrm{Cl}-3.084794$ to -0.354518$), p=0.0178$. 


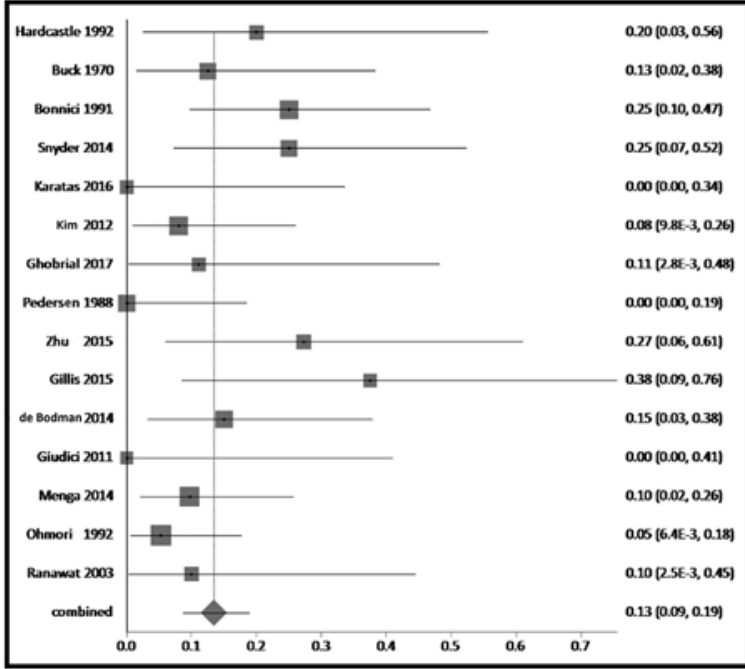

A. Buck's Repair: Pooled complication rate 13\%

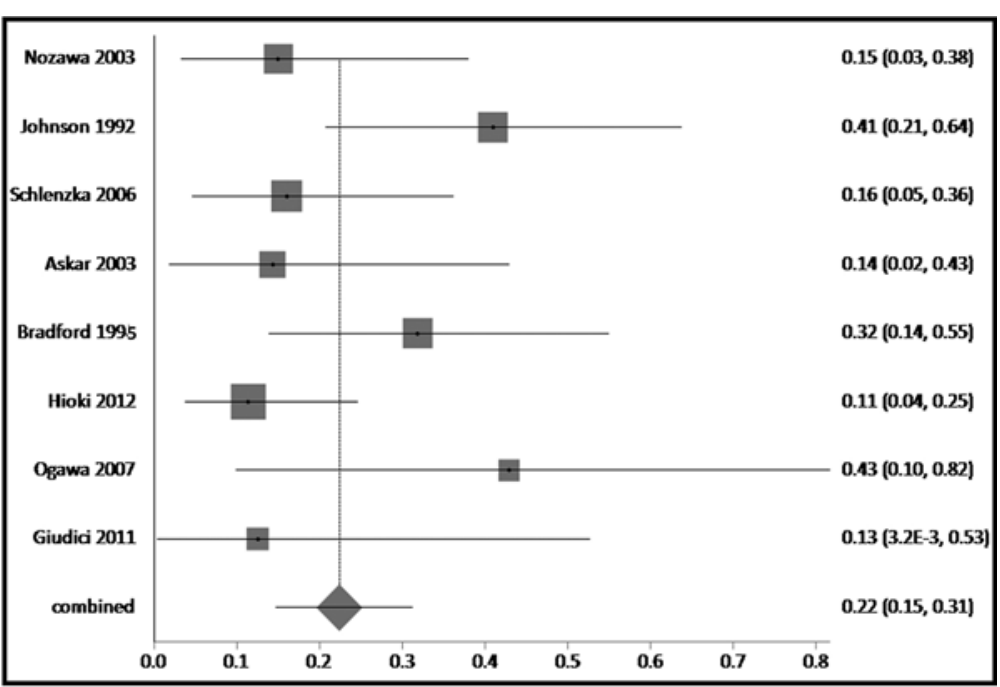

B. Scott's Repair: Pooled complication rate $22 \%$
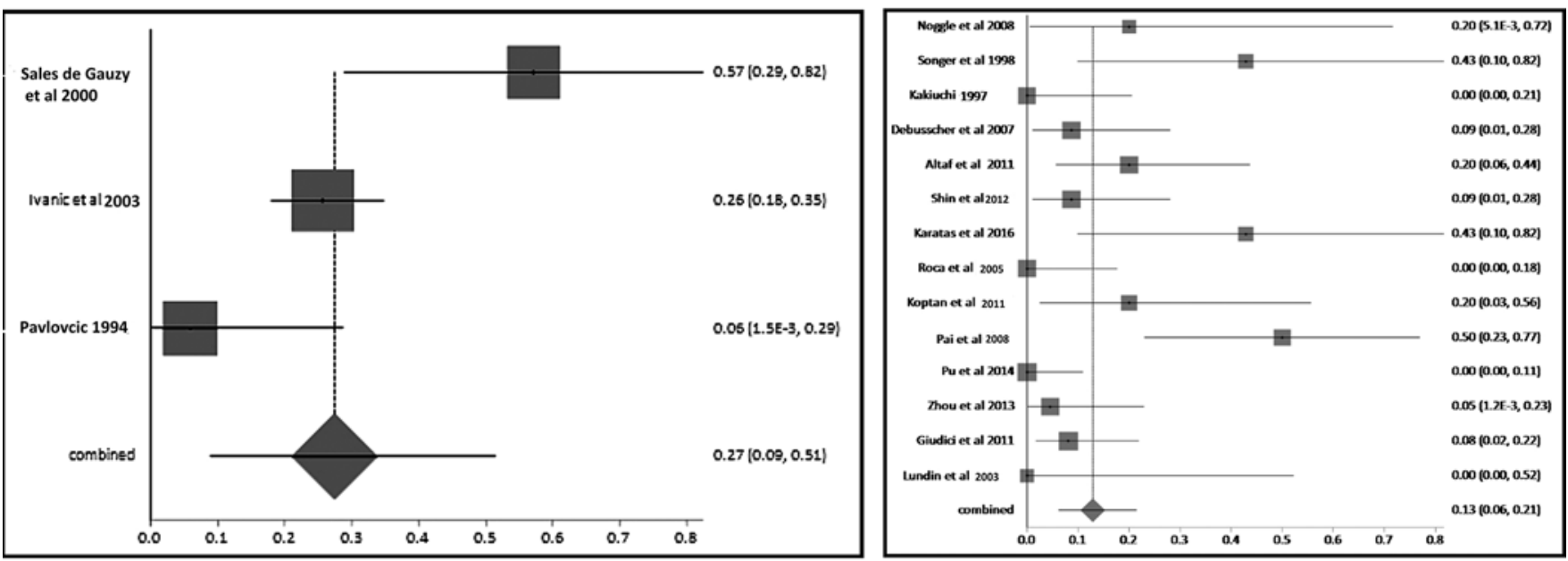

C. Morscher's Repair: Pooled complication rate 27\%

D. Pedicle Repair: Pooled complication rate $13 \%$

FIG. 3. Pooled proportional meta-analysis of the complication rates. A: The Buck repair showed a pooled complication rate of $13 \% . I^{2}=31.5 \%$. Random effects: pooled proportion $=0.134178$ (95\% Cl 0.086908-0.189836). Begg-Mazumdar: Kendall's tau $=0.52381, p=0.0059$. Egger: bias $=1.930049(95 \% \mathrm{Cl} 0.771404-3.088694), p=0.0032$. B: The Scott repair showed a pooled complication rate of $22 \%$. $\left.\right|^{2}=37.1 \%$. Random effects: pooled proportion $=0.223571(95 \% \mathrm{Cl} 0.146507-0.311594)$. Begg-Mazumdar: Kendall's tau $=0.285714, p=0.3988$ (low power). Egger: bias $=2.184051(95 \% \mathrm{Cl}-0.309288$ to 4.677389), $p=0.0758$. C: The Morscher repair showed a pooled complication rate of $27 \%$. $\left.\right|^{2}=80.2$. Random effects: pooled proportion $=$ 0.274245 (95\% Cl 0.088969-0.514053). D: The pedicle screw repair showed a pooled fusion complication rate of $13 \% .\left.\right|^{2}=67.6$. Random effects: pooled proportion $=0.128798$ (95\% Cl 0.062435-0.214551). Begg-Mazumdar: Kendall's tau $=0.662921, p=$ 0.0014. Egger: bias $=2.305739(95 \% \mathrm{Cl} 1.29242$ to 3.319058$), p=0.0003$.

the patient improved completely without any symptoms of pain and returned to work were considered as positive outcomes. A postoperative Oswestry Disability Index score less than 20 was considered a positive outcome. The excellent and good outcomes in the Henderson, Odom, and Macnab criteria were considered as positive outcomes. Patients who had persisting pain or who were unable to return to work due to pain were considered to have had a negative outcome. The pooled positive outcome rates for the Buck, Scott, Morscher, and pedicle screw groups were $84.33 \%, 82.49 \%, 80.30 \%$, and $80.1 \%$, respectively. The favorable outcome rates were lowest for the pedicle screw and the Morscher groups. The best outcomes were seen with the Buck repair. The favorable outcome rate for the minimally invasive Buck repair was better than that for the open Buck repair (Fig. 4).

\section{Discussion}

Direct repair surgeries have gradually evolved from 1968 to the present day use of minimally invasive approaches. Direct repair of the pars interarticularis was first reported by Kimura ${ }^{23}$ in 1968 by using bone graft without the use of internal fixation. After this, Scott in 1986 report- 


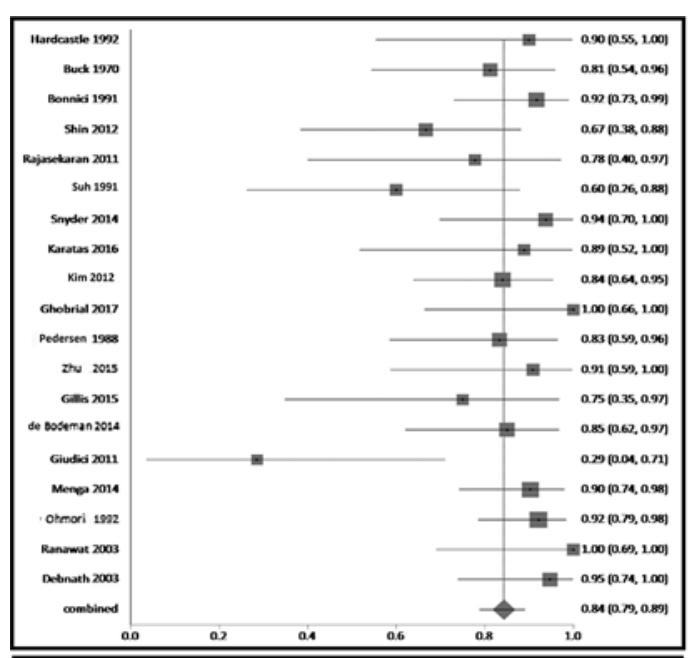

A. Buck's Repair: Pooled outcome rate $84 \%$

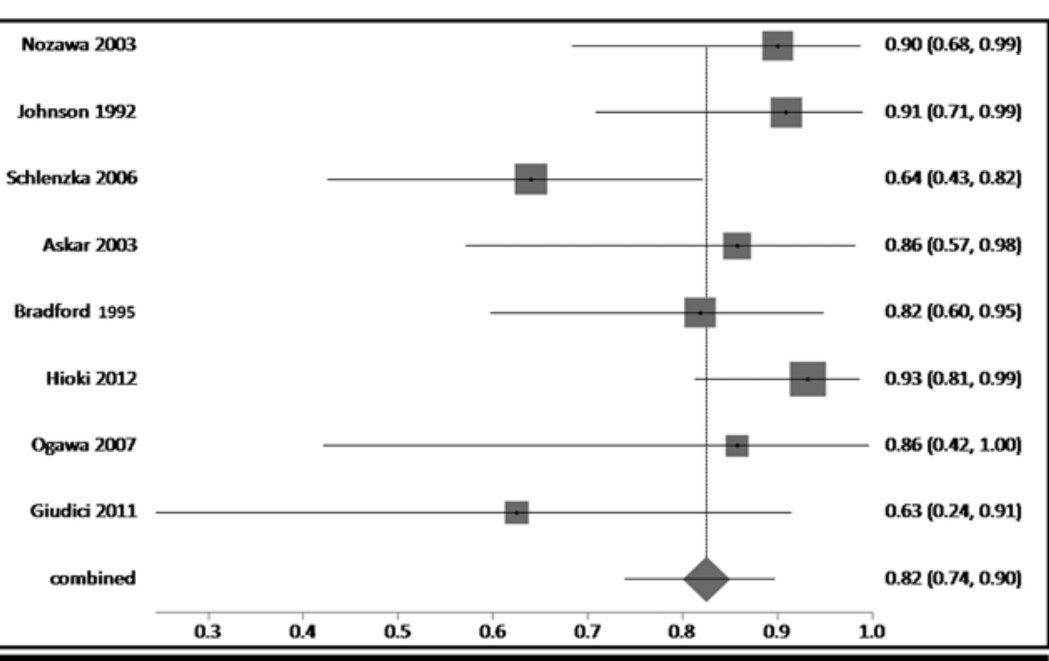

B. Scott's Repair: Pooled outcome rate $82 \%$

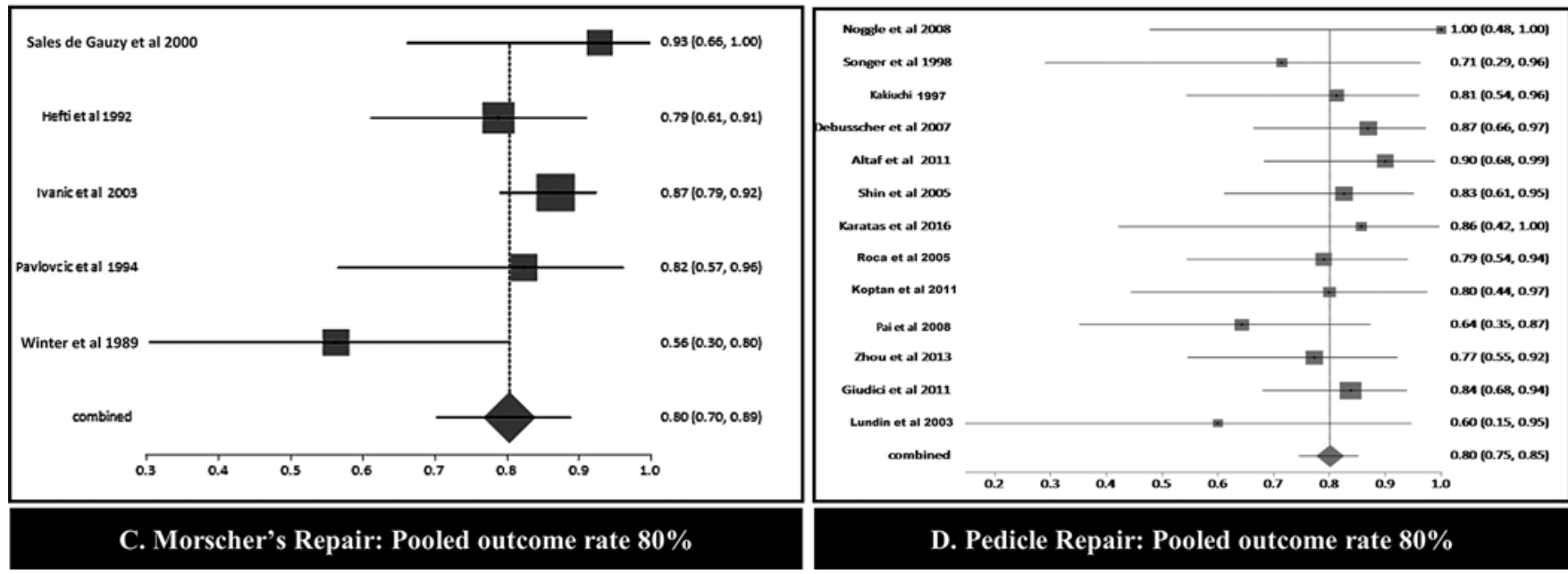

FIG. 4. Pooled proportional meta-analysis of the positive outcome rate. A: The Buck repair showed a pooled outcome rate of $84 \% . I^{2}=36 \%$. Random effects: pooled proportion $=0.843324$ (95\% Cl 0.788331-0.891384). Begg-Mazumdar: Kendall's tau = $-0.625731, p<0.0001$. Egger: bias $=-2.559973(95 \% \mathrm{Cl}-3.908265$ to -1.211681$), p=0.0009$. B: The Scott repair showed a pooled outcome rate of $82 \% . I^{2}=42.1 \%$. Random effects: pooled proportion $=0.824903(95 \% \mathrm{Cl} 0.739211-0.896526)$. BeggMazumdar: Kendall's tau $=-0.571429, p=0.0312$ (low power). Egger: bias $=-2.089109(95 \% \mathrm{Cl}-4.044024$ to -0.134194$)$, $p=0.0399$. C: The Morscher repair showed a pooled outcome rate of $80 \% .\left.\right|^{2}=51.7 \%$. Random effects: pooled proportion $=$ 0.803549 (95\% Cl 0.701775-0.88835). Begg-Mazumdar: Kendall's tau $=-0.6, p=0.0833$ (low power). Egger: bias $=-1.438749$ $(95 \% \mathrm{Cl}-5.109707$ to 2.232209$), p=0.3008$. D: The pedicle screw repair showed a pooled outcome rate of $80 \%$. $\left.\right|^{2}=0 \%$. Random effects: pooled proportion $=0.801237$ (95\% Cl 0.745298-0.851789). Begg-Mazumdar: Kendall's tau $=-0.358974, p=0.0763$. Egger: bias $=-1.138245(95 \% \mathrm{Cl}-2.579258$ to 0.302767$), p=0.11$.

ed the use of a wiring method. In 1970, Buck published his series of direct repairs using a lag screw across the defect in a cohort of fast bowlers. ${ }^{6}$ Morscher et al., ${ }^{28}$ in 1984, reported their method as being especially suited to cases of dysplastic lamina where a Buck repair was not possible. Methods based on pedicle screw insertion and minimally invasive methods are relatively recent (Fig. 5).

A total of 46 studies with 900 patients were finally considered for the study (Fig. 1A).

\section{Buck Repair}

In the Buck method, a single lag screw is passed from the inferior edge of the lamina across the defect after plac- ing the autologous graft into the defect. Biomechanical testing in cadaver spines of the intralaminar screw construct has shown good stability of the spondylotic defect in comparison with the other methods. ${ }^{28}$ The complications of this repair are mainly due to screw loosening or misplacement. ${ }^{1}$ Of the 19 studies that used this form of repair, fusion rates ranged from $42.85 \% \%^{13}$ to $100 \% .15,21,38,48$ The pooled fusion rate was $83.53 \%$. The series by Giudici et al. ${ }^{13}$ reported the lowest fusion rate. The authors opined that accurate screw placement was the main technical difficulty to achieve a good purchase and compression at the site of defect. It was also noted that in some cases, the screw itself occupied much of the space of the defect in the region of the isthmus, which may prevent bony contact 


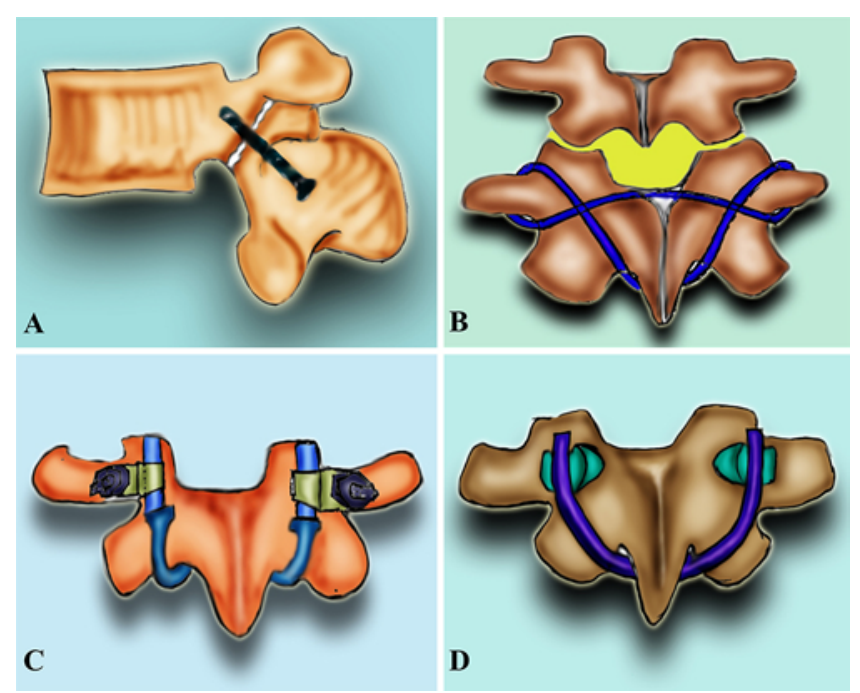

FIG. 5. Schematic diagram showing the different types of direct repairs. A: Buck repair. The screw is passed from the lower edge of the lamina across the defect. B: Scott repair. The wire is encircled around the transverse process and spinous process. C: Morscher repair. Pedicle screw with laminar hooks. D: Pedicle screw with a U-shaped rod. Copyright Anil Nanda. Published with permission.

with the graft. ${ }^{13}$ Screw loosening and screw breakage were the most common complications noted in our study. The complication rate ranged from $0 \%{ }^{21}$ to $37.5 \% .^{12}$ The positive outcome ranged from $28 \%{ }^{13}$ to $100 \% .^{39}$

\section{Scott Repair}

The Scott repair involves a wire that is encircled around the transverse process and spinous process. The procedure is technically less demanding than the other methods of pars repair. However, it requires a wider exposure and muscle dissection, resulting in greater blood loss. ${ }^{1}$ Vascular and nerve root injury can occur when the wire is being encircled across the transverse process, and winding the wire around the transverse process of L-5 might be difficult in cases in which it is close to the sacrum. ${ }^{1}$ In our analysis, the main problem noted in most series employing the Scott method was wire breakage. $2,5,13,17,19,31,32,43$ There were 14 such instances reported. The fusion rates ranged from $43 \%$ to $100 \%, 2,31$ and the overall pooled favorable outcome of the Scott repair was $82.49 \%$.

\section{Morscher Repair}

In the Morscher method, the screw is inserted in the base of the superior articular process. The screw is attached to a laminar hook to achieve approximation of the pars defect. Our analysis showed a high pooled complication rate with the use of this technique (27.42\%). In the series by Sales de Gauzy et al., ${ }^{42}$ there were 8 cases of screw loosening. Ivanic et al..$^{18}$ reported a large series of Morscher repairs (113 patients) with a long follow-up period. The series by Winter and $\mathrm{Jani}^{49}$ reported a fusion rate of only $50 \%$. In the same series, 7 cases of screw loosening were documented. The Morscher repair was associated with the lowest fusion rate and highest complication rate in our study. The small screw purchase in the base of the superior articular process could be responsible for many instances of screw pullout and consequent nonfusion.

\section{Pedicle Screw-Based Repairs}

Pedicle screw-based repairs were first reported by Songer and Rovin in $1988 .{ }^{47}$ In this method, the authors used a pedicle screw to anchor a cable that approximated the pars defect. Other pedicle screw-based methods include using a pedicle screw with laminar hook fixation ${ }^{30}$ and using a pedicle screw with a curved rod running under the spinous process to stabilize the pars defect.1.11 In all of these techniques, the common anchor is the pedicle screw. The pedicle screw provides strong support with a low incidence of screw pullout due to larger bony purchase. Pedicle screw insertion has become an increasingly familiar procedure among surgeons and allows for minimally invasive approaches as well. Analysis of this group showed excellent fusion rates; fusion rates of $100 \%$ were noted in several studies. ${ }^{20,21,25,30,37,47,50}$ The pooled fusion rate was $90.21 \%$. The pedicle screw group had the lowest pooled complication rate of $12.8 \%$. The common complication associated with pedicle screw-based methods involved wire/cable breakage in screw-wire constructs. The pedicle screw-based techniques are associated with the most favorable fusion and lowest complication rates in comparison with the other groups.

Four studies employing the minimally invasive Buck repair with 37 patients were also analyzed..$^{10,12,21,51}$ The minimally invasive series had low complication rates and excellent outcomes. BMP was used to aid fusion in 3 studies. ${ }^{10,21,46}$ All of these studies reported good fusion rates.

Analysis of the data from this study has shown that in patients with spondylolysis and low-grade spondylolisthesis in whom conservative treatment has failed, surgical management substantially improves the outcome and return to activity. Among all studied groups, pedicle screw-based repairs have the best fusion rates and lowest complication rates. Based on this finding, we conclude that the pedicle screw-based repairs are recommended as the repair of choice, followed by the Buck repair. Neither the Scott repair nor the Morscher repair is recommended as the first choice of repair of the pars defect. Patient selection is important in the management of direct repairs. The ideal candidate should have no significant disc degeneration, be young, and have a low-grade spondylolisthesis. Direct repairs are especially suited for young athletes and have shown excellent outcomes.

\section{Justification for Our Analysis}

There are a number of surgical procedures that address direct pars repair with different modifications. Moreover, newer, minimally invasive techniques have been introduced. Because of the large variety of different procedures for direct repair, the procedure of choice becomes unclear. To date, there have been systematic reviews that have addressed this issue, but no meta-analysis has been carried out. However, this study attempts to statistically define the differences in types of direct repairs in reference to the rates of fusion, complications, and outcomes. We were unable to find any randomized controlled trials that addressed this issue. 


\section{Limitations of the Study}

There are a number of limitations of the present study. There were no randomized controlled trials available comparing the different groups. The statistical power of a metaanalysis is highest when randomized controlled trials are included. The present study is a meta-analysis of observational studies. There is a lack of control groups, which can introduce bias. In clinical scenarios, it is not always possible to conduct a meta-analysis. The information in the existing literature, however, cannot be disregarded, and best attempts need to be made to analyze the available data, with an understanding of the included bias that may influence the overall results. The assessment of outcome measures was not standardized in most of the studies. This may introduce discrepancy in the overall assessment of outcome in the study groups. In this study, we combined studies of patients involved in sport activities and those who were not involved in sports into a single analysis. These 2 groups are heterogeneous subsets with different risk factors, and the criteria for assessment of fusion are not well defined in the studies. In some studies, radiography was used, while in others CT scanning was performed. The assessment of fusion using radiographs is less sensitive than that using CT scans, and cases of nonfusion can be potentially missed and judged as fused.

\section{Conclusions}

Pedicle screw-based direct repairs for spondylosis and low-grade spondylolisthesis are the best choice of procedure, with the highest fusion rate and lowest complication rate, followed by the Buck repair. The Morscher repair and Scott repair had high rates of complications and lower fusion rates.

\section{Acknowledgments}

We thank Ms. Julia Esparza, associate librarian, LSU-HSC, for assisting in the search strategy, and Ms. Gloria Caldito, associate professor of statistics and research, LSU-HSC, for assistance with the statistical analysis.

\section{References}

1. Altaf F, Osei NA, Garrido E, Al-Mukhtar M, Natali C, Sivaraman A, et al: Repair of spondylolysis using compression with a modular link and screws. J Bone Joint Surg Br 93:73-77, 2011 (Erratum in J Bone Joint Surg Br 93:566, 2011)

2. Askar Z, Wardlaw D, Koti M: Scott wiring for direct repair of lumbar spondylolysis. Spine (Phila Pa 1976) 28:354-357, 2003

3. Beutler WJ, Fredrickson BE, Murtland A, Sweeney CA, Grant WD, Baker D: The natural history of spondylolysis and spondylolisthesis: 45-year follow-up evaluation. Spine (Phila Pa 1976) 28:1027-1035, 2003

4. Bonnici AV, Koka SR, Richards DJ: Results of Buck screw fusion in grade I spondylolisthesis. J R Soc Med 84:270273, 1991

5. Bradford DS, Iza J: Repair of the defect in spondylolysis or minimal degrees of spondylolisthesis by segmental wire fixation and bone grafting. Spine (Phila Pa 1976) 10:673-679, 1985

6. Buck JE: Direct repair of the defect in spondylolisthesis. Preliminary report. J Bone Joint Surg Br 52:432-437, 1970
7. de Bodman C, Bergerault F, de Courtivron B, Bonnard C: Lumbo-sacral motion conserved after isthmic reconstruction: long-term results. J Child Orthop 8:97-103, 2014

8. Debnath UK, Freeman BJ, Gregory P, de la Harpe D, Kerslake RW, Webb JK: Clinical outcome and return to sport after the surgical treatment of spondylolysis in young athletes. J Bone Joint Surg Br 85:244-249, 2003

9. Debusscher F, Troussel S: Direct repair of defects in lumbar spondylolysis with a new pedicle screw hook fixation: clinical, functional and Ct-assessed study. Eur Spine J 16:16501658,2007

10. Ghobrial GM, Crandall KM, Lau A, Williams SK, Levi AD: Minimally invasive direct pars repair with cannulated screws and recombinant human bone morphogenetic protein: case series and review of the literature. Neurosurg Focus 43(2):E6, 2017

11. Gillet P, Petit M: Direct repair of spondylolysis without spondylolisthesis, using a rod-screw construct and bone grafting of the pars defect. Spine (Phila Pa 1976) 24:1252-1256, 1999

12. Gillis CC, Eichholz K, Thoman WJ, Fessler RG: A minimally invasive approach to defects of the pars interarticularis: Restoring function in competitive athletes. Clin Neurol Neurosurg 139:29-34, 2015

13. Giudici F, Minoia L, Archetti M, Corriero AS, Zagra A: Long-term results of the direct repair of spondylolisthesis. Eur Spine J 20 (Suppl 1):S115-S120, 2011

14. Hardcastle P, Annear P, Foster DH, Chakera TM, McCormick C, Khangure M, et al: Spinal abnormalities in young fast bowlers. J Bone Joint Surg Br 74:421-425, 1992

15. Hardcastle PH: Repair of spondylolysis in young fast bowlers. J Bone Joint Surg Br 75:398-402, 1993

16. Hefti F, Seelig W, Morscher E: Repair of lumbar spondylolysis with a hook-screw. Int Orthop 16:81-85, 1992

17. Hioki A, Miyamoto K, Sadamasu A, Nozawa S, Ogawa H, Fushimi K, et al: Repair of pars defects by segmental transverse wiring for athletes with symptomatic spondylolysis: relationship between bony union and postoperative symptoms. Spine (Phila Pa 1976) 37:802-807, 2012

18. Ivanic GM, Pink TP, Achatz W, Ward JC, Homann NC, May M: Direct stabilization of lumbar spondylolysis with a hook screw: mean 11-year follow-up period for 113 patients. Spine (Phila Pa 1976) 28:255-259, 2003

19. Johnson GV, Thompson AG: The Scott wiring technique for direct repair of lumbar spondylolysis. J Bone Joint Surg Br 74:426-430, 1992

20. Kakiuchi M: Repair of the defect in spondylolysis. Durable fixation with pedicle screws and laminar hooks. J Bone Joint Surg Am 79:818-825, 1997

21. Karatas AF, Dede O, Atanda AA, Holmes L Jr, Rogers K, Gabos P, et al: Comparison of direct pars repair techniques of spondylolysis in pediatric and adolescent patients: pars compression screw versus pedicle screw-rod-hook. Clin Spine Surg 29:272-280, 2016

22. Kim YT, Lee H, Lee CS, Lee DH, Hwang CJ, Ahn TS: Direct repair of the pars interarticularis defect in spondylolysis. J Spinal Disord Tech [epub ahead of print], 2012

23. Kimura M: [My method of filing the lesion with spongy bone in spondylolysis and spondylolisthesis.] Seikei Geka 19:285296, 1968 (Jpn)

24. Koptan WMT, ElMiligui YH, ElSharkawi MM: Direct repair of spondylolysis presenting after correction of adolescent idiopathic scoliosis. Spine J 11:133-138, 2011

25. Lundin DA, Wiseman D, Ellenbogen RG, Shaffrey CI: Direct repair of the pars interarticularis for spondylolysis and spondylolisthesis. Pediatr Neurosurg 39:195-200, 2003

26. Menga EN, Jain A, Kebaish KM, Zimmerman SL, Sponseller PD: Anatomic parameters: direct intralaminar screw repair of spondylolysis. Spine (Phila Pa 1976) 39:E153-E158, 2014 
27. Meyerding HW: Spondylolisthesis. Surg Gynecol Obstet 54:371-377, 1932

28. Morscher E, Gerber B, Fasel J: Surgical treatment of spondylolisthesis by bone grafting and direct stabilization of spondylolysis by means of a hook screw. Arch Orthop Trauma Surg 103:175-178, 1984

29. Nicol RO, Scott JH: Lytic spondylolysis. Repair by wiring. Spine (Phila Pa 1976) 11:1027-1030, 1986

30. Noggle JC, Sciubba DM, Samdani AF, Anderson DG, Betz RR, Asghar J: Minimally invasive direct repair of lumbar spondylolysis with a pedicle screw and hook construct. Neurosurg Focus 25 (2):E15, 2008

31. Nozawa S, Shimizu K, Miyamoto K, Tanaka M: Repair of pars interarticularis defect by segmental wire fixation in young athletes with spondylolysis. Am J Sports Med 31:359-364, 2003

32. Ogawa H, Nishimoto H, Hosoe H, Suzuki N, Kanamori Y, Shimizu K: Clinical outcome after segmental wire fixation and bone grafting for repair of the defects in multiple level lumbar spondylolysis. J Spinal Disord Tech 20:521-525, 2007

33. Ohmori K, Suzuki K, Ishida Y: Translamino-pedicular screw fixation with bone grafting for symptomatic isthmic lumbar spondylolysis. Neurosurgery 30:379-384, 1992

34. Pai VS, Hodgson B, Pai V: Repair of spondylolytic defect with a cable screw reconstruction. Int Orthop 32:121-125, 2008

35. Pavlovcic V: Surgical treatment of spondylolysis and spondylolisthesis with a hook screw. Int Orthop 18:6-9, 1994

36. Pedersen AK, Hagen R: Spondylolysis and spondylolisthesis. Treatment by internal fixation and bone-grafting of the defect. J Bone Joint Surg Am 70:15-24, 1988

37. Pu X, Yang S, Cao H, Jing X, Yin J: [Effectiveness of Ushape titanium screw-rod fixation system with bone autografting for lumbar spondylolysis of young adults.] Zhongguo Xiu Fu Chong Jian Wai Ke Za Zhi 28:354-357, 2014 (Chinese)

38. Rajasekaran S, Subbiah M, Shetty AP: Direct repair of lumbar spondylolysis by Buck's technique. Indian J Orthop 45:136-140, 2011

39. Ranawat VS, Dowell JK, Heywood-Waddington MB: Stress fractures of the lumbar pars interarticularis in athletes: a review based on long-term results of 18 professional cricketers. Injury 34:915-919, 2003

40. Reitman CA, Esses SI: Direct repair of spondylolytic defects in young competitive athletes. Spine J 2:142-144, 2002

41. Roca J, Iborra M, Cavanilles-Walker JM, Albertí G: Direct repair of spondylolysis using a new pedicle screw hook fixation: clinical and CT-assessed study: an analysis of 19 patients. J Spinal Disord Tech 18 Suppl:S82-S89, 2005

42. Sales de Gauzy J, Vadier F, Cahuzac JP: Repair of lumbar spondylolysis using Morscher material: 14 children followed for 1-5 years. Acta Orthop Scand 71:292-296, 2000

43. Schlenzka D, Remes V, Helenius I, Lamberg T, Tervahartiala $\mathrm{P}$, Yrjönen T, et al: Direct repair for treatment of symptomatic spondylolysis and low-grade isthmic spondylolisthesis in young patients: no benefit in comparison to segmental fusion after a mean follow-up of 14.8 years. Eur Spine J 15:14371447, 2006

44. Sherman FC, Rosenthal RK, Hall JE: Spine fusion for spondylolysis and spondylolisthesis in children. Spine (Phila Pa 1976) 4:59-66, 1979

45. Shin MH, Ryu KS, Rathi NK, Park CK: Direct pars repair surgery using two different surgical methods: pedicle screw with universal hook system and direct pars screw fixation in symptomatic lumbar spondylosis patients. J Korean Neurosurg Soc 51:14-19, 2012

46. Snyder LA, Shufflebarger H, O'Brien MF, Thind H, Theodore N, Kakarla UK: Spondylolysis outcomes in adolescents after direct screw repair of the pars interarticularis. J Neurosurg Spine 21:329-333, 2014

47. Songer MN, Rovin R: Repair of the pars interarticularis defect with a cable-screw construct. A preliminary report. Spine (Phila Pa 1976) 23:263-269, 1998

48. Suh PB, Esses SI, Kostuik JP: Repair of pars interarticularis defect. The prognostic value of pars infiltration. Spine (Phila Pa 1976) 16 (8 Suppl):S445-S448, 1991

49. Winter M, Jani L: Results of screw osteosynthesis in spondylolysis and low-grade spondylolisthesis. Arch Orthop Trauma Surg 108:96-99, 1989

50. Zhou Z, Song Y, Zeng J, Liu H, Liu L, Kong Q, et al: [Effectiveness of posterior intrasegmental fixation with pedicle screw-lamina hook system in treatment of lumbar spondylolysis.] Zhongguo Xiu Fu Chong Jian Wai Ke Za Zhi 27:274-277, 2013 (Chinese)

51. Zhu X, Wang J, Zhou Y, Zhang Z, Li C, Zheng W: [Minimally invasive surgery for direct repair of lumbar spondylolysis by utilizing intraoperative navigation and microendoscopic techniques.] Zhongguo Xiu Fu Chong Jian Wai Ke Za Zhi 29:1244-1248, 2015 (Chinese)

\section{Disclosures}

The authors report no conflict of interest concerning the materials or methods used in this study or the findings specified in this paper.

\section{Author Contributions}

Conception and design: Nanda, Mohammed. Acquisition of data: Mohammed, Narayan. Analysis and interpretation of data: Nanda, Mohammed, Patra, Narayan. Drafting the article: Nanda, Mohammed, Patra. Critically revising the article: Nanda, Mohammed, Patra. Reviewed submitted version of manuscript: Nanda, Mohammed, Patra. Approved the final version of the manuscript on behalf of all authors: Nanda. Statistical analysis: Mohammed. Administrative/technical/material support: Nanda, Mohammed, Patra, Savardekar, Dossani, Bollam. Study supervision: Nanda, Mohammed, Savardekar, Bollam, Bir.

\section{Correspondence}

Anil Nanda: LSU-HSC, Shreveport, Louisiana. ananda@ lsuhsc.edu. 